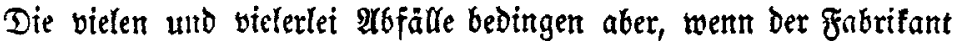
miđt mit @iaden arbeitèn mill, Deren Bertwendung, Die aber ebenjo vielfeitig ift. So lönnen ganze Stămme vorlăufig zu groben Brettern zerfönitten, und biejenigen babon, aus weldjen nichts Bepiperes Gerausigebiatit werben fann, alsె folde verfauft werbẹn. Andere Stüđe geben Trommeliärge, Siebränder, Sđjađtelthol $\mathfrak{z}_{3}$

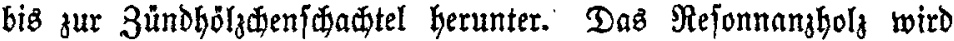

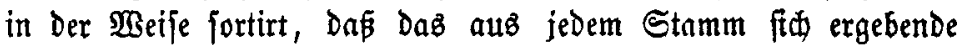

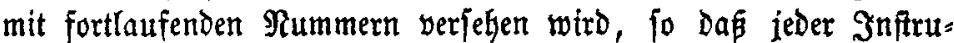
mentenmađer auf Berlangen jo viel zufammengehorige Theile eineż Baumes haben fann, als Derfelbe gegeben hat, alfo größere Rejonnamböben u. $\lceil. \mathfrak{w}$. aus Theilen Deffelben Baumes zufammens jesten fann. Das Şol wird zu affer Saiteninfrutmenten ver.

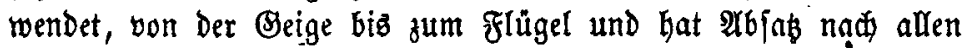
Begenten Der Erde. Das befte Solz foll meift yon den Engländern behalten werden; Dieje jollen eż 20,30 und mehr $3 a \mathfrak{b r e}$ liegen

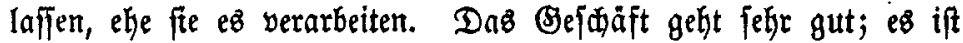
ftets nur wentg Snfrumententyol habe mid bielfach exfundigt, ob nidit aud Beistannentyoly von

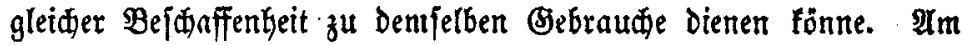
einen Drte fommt foldes niøt yor, an einem andern wurbe metne Frage gerabegu mit nein, an einem britten aużmeidfend beantwortet, ober man fagte mir, Daß bie Snftrumentenmadier. nur - Fidiftentiol;

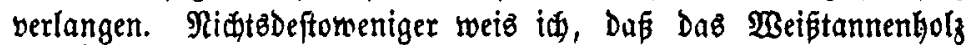
yon derjęben Beffiaffenteit ebenfalls benupt und in Den SyandeI gebradit wird; jelten wird aud jeder Snfrumentenmadier eŝ vom Fidjtentyolz zu unterfdetben wiffen, und $d \mathfrak{a}$ man Darüber feine

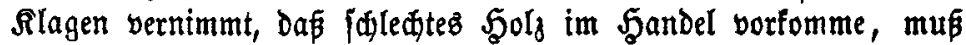
es eben gleiđfalls taugliø jein.

(StiluB folgt.)

\title{
3agdwe [rn.
}

Signale ber R. Şanntover'jăhen Jägerei.

Wir glauben vielen umferet Rejer ein Bergnitgen bereiten zu fönnen, wenn wir bieje Signale, weldte auf Dem Bủgelforn bei Den Dortigen Sagden geblaien werden, nach einer unz mitgetheilten Sammlung veröffentlidien. 